13. Mollaret H. Conservation du bacille de la peste durant 28 mois en terrier arti? ciel: demonstration experimentale de la conservation interepizootique de las peste dans ses foyers inveteres. CR Acad Sci Paris. 1968;267:972-3.

14. Mollaret HH. Experimental preservation of plague in soil [in French]. Bull Soc Pathol Exot Filiales. 1963;56:1168-82.

15. Chu MC. Laboratory manual of plague diagnostics. Geneva: US Centers for Disease Control and Prevention and World Health Organization; 2000

16. Centers for Disease Control and Prevention. Imported plague-New York City, 2002. MMWR Morb Mortal Wkly Rep. 2003;52:725-8.

17. Darby C, Hsu JW, Ghori N, Falkow S. Caenorhabditis elegans: plague bacteria bio? lm blocks food intake. Nature. 2002;417:243-4.
18. Rose LJ, Donlan R, Banerjee SN, Arduino MJ. Survival of Yersinia pestis on environmental surfaces. Appl Environ Microbiol. 2003;69:2166-71.

Address for correspondence: Rebecca J. Eisen, Centers for Disease Control and Prevention, 3150 Rampart Rd, Fort Collins, CO 80521, USA; email: rjeisen@cdc.gov

The opinions expressed by authors contributing to this journal do not necessarily re? ect the opinions of the Centers for Disease Control and Prevention or the institutions with which the authors are af? liated.

\title{
Plague Victims Catapulted Over Walls Into Besieged City
}

\section{Thomas Lux}

Early germ

warfare. The dead

hurled this way turn like wheels

in the sky. Look: there goes

Larry the Shoemaker, barefoot, over the wall, and Mary Sausage Stuffer, see how she ?ies, and the Hatter twins, both at once, soar over the parapet, little Tommy's elbow bent as if in a salute, and his sister, Mathilde, she follows him, arms outstretched, through the air, just as she did on earth.

From The Street of Clocks. New Yori: Houghton Mif?in Co.; 2001. Published with permission of the author.

Thomas Lux is author of several books of poetry and recipient of many poetry awards. He holds the Bourne Chair in Poetry at the Georgia Institute of Technology, Atlanta, Georgia, where he runs the poetry program. 